\title{
Participation of adolescents in the Family Health Strategy from the theoretical-methodological structure of an enabler to participation
}

\author{
Roberta Peixoto Vieira ${ }^{1}$ \\ Sílvia Helena Pereira Gomes² \\ Maria de Fátima Antero Sousa Machado ${ }^{3}$ \\ Italla Maria Pinheiro Bezerra ${ }^{4}$ \\ Caroline Antero Machado ${ }^{5}$
}

\begin{abstract}
Objective: to evaluate the participation of adolescents in the Family Health Strategy, from the theoretical-methodological structure of an enabler to participation. Method: a quantitative study, conducted from December of 2010 to March of 2011, with 213 professionals in the FHS in the region of Cariri-Ceará-Brazil. Data were collected through a questionnaire and organized in SPSS 18.0. Results: the level of normative participation becomes manifest beginning with the adolescent search for health services, motivated by disease (77.9\%). Normative participation + independence appear when they seek prenatal care and family planning. Emancipatory participation was identified by the frequency of adolescents in group activities, in the schools, and a move in the direction of the level of transformative participation was observed. Conclusion: in this context, it is understood that there exists a need to stimulate the participatory process of the adolescents for a change in health promotion in this group.
\end{abstract}

Descriptors: Adolescent; Family Health; Consumer Participation.

\footnotetext{
${ }^{1}$ Master's student, Universidade Estadual do Ceará, Fortaleza, CE, Brazil. Professor, Universidade Regional do Cariri, Unidade Descentralizada Iguatu, Departamento de Enfermagem, Iguatu, CE, Brazil. Professor, Faculdade Vale do Salgado, Icó, CE, Brazil.

2 Master's student, Universidade Federal de Pernambuco, Recife, PE, Brazil.

${ }^{3} \mathrm{PhD}$, Associate Professor, Universidade Regional do Cariri, Crato, CE, Brazil.

${ }^{4}$ Doctoral student, Faculdade de Medicina do ABC, Santo André, SP, Brazil. Professor, Universidade Regional do Cariri, Crato, CE, Brazil. Professor, Faculdade de Juazeiro do Norte, Juazeiro do Norte, CE, Brazil.

${ }_{5}^{5}$ MSc, Professor, Faculdade Maurício de Nassau, Fortaleza, CE, Brazil.
}

Corresponding Author:

Roberta Peixoto Vieira

Universidade Regional do Cariri. Unidade Descentralizada Iguatu

Departamento de Enfermagem

Rua Dr. Vicente Bezerra da Costa, 21

Bairro: São Sebastião

CEP: 63500-250, Iguatu, CE, Brasi

E-mail: roberta.peixotovieira@gmail.com
Copyright () 2014 Revista Latino-Americana de Enfermagem This is an Open Access article distributed under the terms of the Creative Commons Attribution Non-Commercial License (CC BY-NC).

This license lets others distribute, remix, tweak, and build upon your work non-commercially, and although their new works must also acknowledge you and be non-commercial, they don't have to license their derivative works on the same terms. 


\section{Introduction}

It was understood that the development of actions directed at adolescents, whether in the area of health or not, requires a broader focus, encompassing not only the technical and biological aspects, but also the psychosocial, historical, social, cultural, political, value, and behavioral aspects ${ }^{(1)}$, the purely biologistic vision does not enable the process of understanding the adolescent in his entirety, restricting the relationships and the addressing of the needs of this audience.

Given this complexity of the care of the adolescent, with regard to their experiences and manifestations during situations of vulnerabilities, especially those related to their health, it can be affirmed that the Family Health Strategy (FHS) is regarded as a health care model that can promote a change of adolescent health, through the capacity to promote continuous comprehensive care, supported by the principles of the Unified Health System (SUS) ${ }^{(2)}$.

Despite the relevance of the FHS, toward adolescent health we find, in the routine care of the Basic Health Units (BHU), a low frequency of adolescents in care and little offered in terms of specific actions for them, showing that actions aimed at their health are falling $\operatorname{short}^{(3)}$.

There exists, therefore, the need for effecting existing public policies to broaden access of the adolescents to health services and changes in the practices of the professionals in family health(1), who are responsible for the development of actions that suit local needs and the peculiarities of care for adolescents(4), and recruitment strategies that facilitate access to and strengthening of relationships.

The magnification of such access aims to provide the consolidation of comprehensive health care for this group, while stimulating the participation of the adolescents in primary care services, contributing to improving their quality of life and, consequently, changing the profile of health in the community.

At this point, a reference is made to the relevance of the participatory process of adolescents, aimed at health promotion and effectuation of the Unified Health System, which can be evidenced through the conceptualization of the term, health promotion, as a process of community empowerment to act on improving the quality of life and health, involving a greater participation in control of this process ${ }^{(5)}$.

This participation allows the individual to form a critical awareness of the reality in which he belongs, and, from that, he can become autonomous and emancipated. This type of participation is known as an enabler to participation, whose goal is to establish a participatory process, because it is an important task for health professionals, to develop and enhance the participatory action and skills of individuals, so that they can exercise a social force and act in supporting the community(6).

In this sense, FHS professionals should recognize the level of participation of the adolescents in the health services, the influence of the process of participation in their promotion of health, to reflect about the relevance of their actions and to use these findings in the redirection of care practices.

From the reflections raised here, this study was conducted based on the following guiding questions: What are the forms of participation of adolescents in the Family Health Strategy? What is the level of participation of adolescents in the FHS? What actions are performed by the professionals of the FHS toward the participation of the adolescents? What difficulties are emphasized by these professionals in the process of adolescent participation? In order to respond to these questions, the objective was to evaluate the participation of adolescents in the Family Health Strategy based on the theoretical-methodological structure of an enabler to participation.

\section{Method}

This was a descriptive, exploratory study, crosssectional in nature, financed by the Ceará Foundation for Scientific and Technological Development (FUNCAP), conducted in municipalities in the Cariri Region, in the south of the state of Ceará, Barbalha, Crato and Juazeiro do Norte, in addition to adopting a quantitative approach. The population of the study included dental surgeons, nurses and physicians working in the FHS in the aforementioned municipalities.

The process of probabilistic approach was that of stratified sampling, in which the number of professionals in each class, working at the Basic Health Units, was stratified according to the municipalities. In each stratum, the sample size was calculated considering a margin of error of 10 percentage points ( $p p)$, a level of confidence of $95 \%$ and a ratio $p=0.5$, so as to maximize the size of the sample.

Data were collected from December of 2010 to March of 2011, a period in which there were 110 Family Health Teams deployed in the three municipalities (21 in Barbalha, 28 in Crato and 61 in Juazeiro do Norte), 
totaling 289 professionals. Based on the calculation of sample size, there were 213 subjects who participated in the study. A random sorting of health units was performed in the Excel program.

The technique employed for data collection was the application of a questionnaire, constructed from the guidelines recommended by the Ministry of Health(7), relating to actions that should be offered to adolescents in primary care. The questionnaire addressed issues that dealt with the actions developed and the mode of participation of the adolescents, in these moments offered in the FHS, and thus classifying them, with reference to the levels of participation of the theoretical structure.
The variables were analyzed descriptively (frequency, mean, standard deviation, etc.) and comparitively. When the variables were dichotomous and/or categorical, the chi-square test was utilized. The level of significance used for the statistical tests was 0.005 . Data were organized with the support of the SPSS 18.0 program (SPSS for Windows, SPSS Inc., Chicago, IL, USA).

The discussion of the results was based on the literature about the theme, and the level of participation of the adolescents was identified from the use of the theoretical-methodological structure of an enabler of participation $^{(8)}$ (Figure 1).

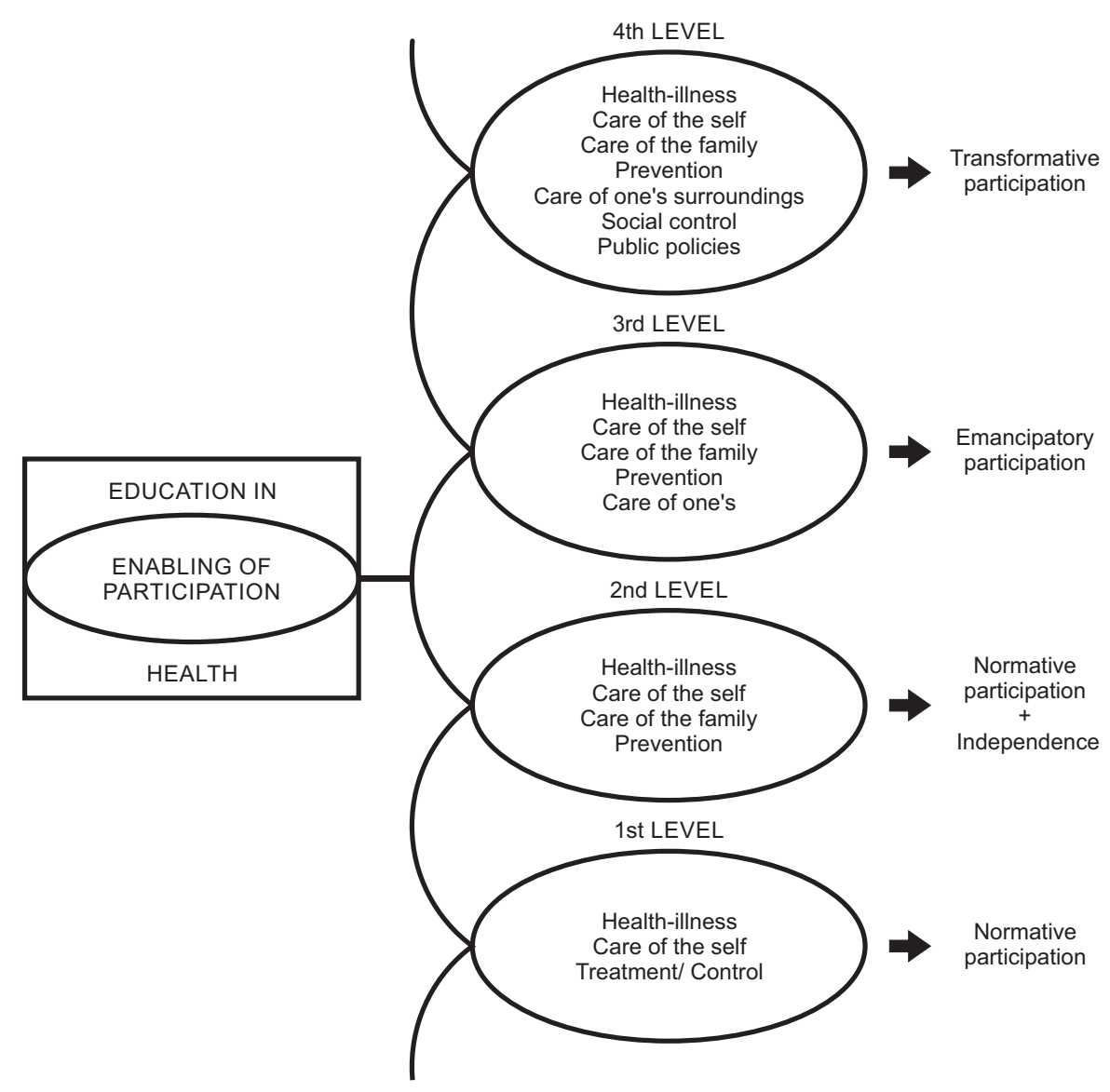

Figure 1 - Theoretical-methodological structure of an enabler of participation.

Fortaleza, Brazil, 2006

This theoretical framework was created to identify the levels of changes occurring in the individuals and their family, along with their incorporation in the Family Health Strategy, classifying the participation of the users of the FHS at different levels ${ }^{(8)}$.
The first level represents normative participation, in which the user is able to care for himself, with emphasis on the treatment and control of the condition. In the present study, this level was identified when the professionals mentioned that the pursuit of health 
services by adolescents was guided only by aspects related to illness, such as consults, marking of exams, and delivering of medicines.

At the second level of the theoretical structure, normative participation + independence, user participation is extended to the development of an awareness that it is necessary not only to care for one's self, but also to take care of the family, performing preventive activities ${ }^{(8)}$. It was identified when the adolescents, according to the professionals of the units, sought care for preventive actions, such as searching for condoms, immunization, family care and other situations that denoted a preventive action.

The third level occurred when the user extended his participation to also taking care of his surroundings, which is called emancipatory participation. One could illustrate this level, in the present study, when it was cited by the professionals that adolescents experienced some action at the school or in the community, focusing on promotion of their health.

At the fourth level, the user takes care of himself, his family, his surroundings, and there is an understanding of and involvement with public policy, representing transformative participation(8). In this study, this level was not identified, which is understood in that adolescents had not lived experiences as those described for the fourth level.

Thus, taking as a reference the levels of the theoretical structure, we sought, beginning with the study conducted together with the adolescents in the FHS, to evaluate the actions developed by professionals, classifying them into these referred levels. This study was approved by the Ethics Committee in Research of the Universidade Regional do Cariri, under Opinion No. 38/2010.

\section{Results}

\section{Profile of the professionals of the Family Health Strategy}

The study sample consisted of 59 dentists, 78 nurses, and 76 physicians, making a total of 213 professionals ( 52 professionals from the municipality of Barbalha, 59 from Crato, and 102 from Juazeiro do Norte). The mean age of study participants was 38.14 $( \pm 11.6)$, with a minimum age of 22 and maximum age of 73.The following were other characteristics evidenced in the profiles of professionals of the FHS (Table 1).
Table 1 - Profile of the professionals of the Family Health Strategy. Barbalha, Crato and Juazeiro do Norte, CE, Brazil, 2011

\begin{tabular}{|c|c|c|}
\hline Variable & $\mathbf{n}$ & $\%$ \\
\hline \multicolumn{3}{|l|}{ Sex } \\
\hline Male & 85 & 39.9 \\
\hline Female & 128 & 60.1 \\
\hline \multicolumn{3}{|l|}{ Locality } \\
\hline Urban area & 174 & 81.7 \\
\hline Rural area & 39 & 18.3 \\
\hline \multicolumn{3}{|l|}{ Working time in the FHS } \\
\hline Not stated & 2 & 0.9 \\
\hline Less than 1 year & 14 & 6.6 \\
\hline Between 1 and 2 years & 32 & 15 \\
\hline Between 3 and 5 years & 52 & 24.4 \\
\hline Between 6 and 9 years & 68 & 31.9 \\
\hline More than 10 years & 45 & 21.1 \\
\hline \multicolumn{3}{|l|}{ Specialization in Family Health } \\
\hline Yes & 122 & 57.3 \\
\hline No & 91 & 42.7 \\
\hline
\end{tabular}

\section{Participation of the adolescents in the Family Health Strategy}

Considering the care of the users in the health units, it was inquired of the professionals which groups were most frequently seen, considering the care inside the unit or in activities outside of it. It was observed that $70.9 \%$ indicated women, followed by the elderly $(64.8 \%)$, children $(56.3 \%)$, adolescents $(27.2 \%)$, and men $(11.7 \%)$. It is worth noting that the sum exceeds $100 \%$, given that the professionals could select more than one option, the same occurs with the other variables in the study.

A considerable percentage of them (31.9\%) believed that the adolescents of their ascribed territory participated in the actions proposed by the team of family health.

With regard to the services offered to the adolescent in primary care, the professionals identified that they were mostly present in individual care (94.8\%), independent of the principle motive; followed by the involvement of the adolescents in group activities/educational activities (55.9\%); participation in intersectoral activities (activities developed in schools, community centers, churches, among others) (51.2\%); home visits (43.2\%); and, only $12.7 \%$ of the professionals considered that adolescents participated in strategies of youth participation (strengthening autonomy).

Concerning the individual care, there was a predominance of curative actions, prenatal and family 
planning, by virtue of the monitoring of the evolution and the process that represented a basic action of monitoring the health of the adolescent (Table 2).

Table 2 - Participation of the adolescent in individual care. Barbalha, Crato and Juazeiro do Norte, CE, Brazil, 2011

\begin{tabular}{lcc}
\hline \multicolumn{1}{c}{ Variable } & $\mathbf{n}$ & $\%$ \\
\hline When they are ill & 166 & 77.9 \\
Prenatal & 157 & 73.7 \\
Reproductive planning & 143 & 67.1 \\
Dental treatment & 135 & 63.4 \\
Immunization care & 127 & 59.6 \\
Monitoring of growth and development & 55 & 25.8 \\
\hline
\end{tabular}

More than half of the professionals affirmed that adolescents participated in the actions proposed by the basic unit, this being participation restricted to individual care. In turn, this type of care, in light of the theoretical-methodological structure of an enabler to participation, was considered as strong presence of the first level of the standard, normative participation (pre-contemplation), when observing the predominance of adolescent participation in curative actions, with emphasis on disease and/or treatment of a condition.

The second level of the standard, that indicated normative participation + independence (contemplation), was identified when the professionals in this study also reported a large participation of the adolescents in prenatal care and family planning, in which they spent time taking care not only of themselves, but also adding the descriptor, care of the family, through care during pregnancy, or acting responsibly in terms of birth control.

In the normative participation + independence, the user already displayed activities of prevention. However, by the data collected in the study, the participation of the adolescent, according to the professionals, in the immunization service, monitoring of growth and development, and educational process at the individual level is still incipient.

As for the realization of group activities with adolescents, $37.1 \%$ of the professionals cited that they did not perform these activities. Among the professionals who performed them, the participatory process was centered on actions developed in schools (55.4\%), games and workshops on the unit $(9.9 \%)$ and in groups of life experiences (8.9\%).

The participative process of adolescents in the activities of education in health were centered on the actions developed in schools, since the actions performed in the Basic Health Unit have not yet become a reality.

Emancipatory participation (determination/ preparation) was identified, representing the third level, when elements indicated caring for one's surroundings, and where adolescents practiced actions in the school focusing on health promotion.

The participation of the adolescents in the home visit developed, primarily, when they were pregnant or postpartum (59.6\%) or when they were sick (45.1\%). This activity also occurred, to a lesser extent, when they wanted to identify situations of risk $(33.8 \%)$, capture patients who did not adhere to treatment (31.9\%), and invite them to educational activities (28.2\%).

When the adolescents were contemplated for a home visit, it occurred principally when they were pregnant/ postpartum or when they were ill, physically incapacitated to travel to the unit. These elements characterized the passivity of the subjects in terms of such activities, and normative participation of the adolescents.

We inquired of the professionals on the team if they stimulated the participation of adolescents in the services of the unit; $93 \%$ of the professionals affirmed doing so through welcoming actions (86.4\%), the approximation with the spaces of insertion of the adolescents (26.3\%), performing mobilization for debates about health conditions and campaigns (21.6\%) involving the adolescents in the evaluation of the services and actions of the $\mathrm{BHU}(21.1 \%)$, in social control activities (7.5\%), and identification and valuing of the student leaders and youth of the community ( $8.9 \%)$.

A movement to the fourth level could be observed that represented the transformative participation (action/maintenance), as well as the other descriptors, participation in the actions of public policies and social control. Right now, the professionals affirmed that they stimulated the participation of the adolescents in the evaluation of the services and actions of the health unit, in the debates about the conditions of health of the neighborhood, campaigns involving the adolescents. However, this level was not yet consolidated, since the percentage of variables related to the fourth level was very low.

As for the accomplishment of intersectoral activities, $75.6 \%$ of the professionals affirmed performing these. They occurred through the support of health education activities, realized in schools $(60.1 \%)$, disclosure in groups and schools of the services offered by the health unit (43.2\%), seeking support from schools and community groups (29.6\%), through the meetings with 
professionals of the social infrastructure existing in the community $(22.1 \%)$, and through linkages with other secretariats of the municipality $(10.8 \%)$

When we solicited the professionals to signal difficulties related to adolescent participation in the FHS, only $15 \%$ of them indicated that there was no difficulty in group participation. Among the problems identified, there was a lack of availability of the professionals to carry out the actions imposed by the service organization $(43.7 \%)$, the fact that the adolescents did not know actions offered to them in UBASF $(42.3 \%)$, the health service did not have specific actions for adolescents (26.3\%), and an inability of professionals to work with this group (14.6\%).

In conducting the group activities, one can also consider that one of the elements for the nonparticipation of adolescents in such activities is the little initiative of the professionals in conduct such moments, where the dentists were the professional category that performs such activities least $(p>0.001)$. They were also identified as the professionals who performed intersectoral activities least ( $p>0.001)$, and those who performed support at the schools least $(p>0.001)$.

\section{Discussion}

The study showed that women, children and elderly represented groups of users most frequently seen in the Basic Health Units. Conversely, the adolescents included, along with the men, were among the groups that were least attended.

The discussion about adolescent health is still in its infancy, which may reflect the national health policy that, for decades, prioritized, in its general guidelines, assistance to the maternal-child group ${ }^{(9)}$. It is observed, then, that there is a weakness in the actions directed toward adolescent health, in detriment to the actions of child, adult and elderly health(10).

In the present study, the adolescents who participated in the actions offered by the unit had an emphasis on curative actions, observing the normative level of participation. This was similar to another study that used the theoretical-methodological structure of enabler to participation, in which user participation in the FHS was subject to disease. The link of the users with the team was established based on consults and search for medication(6).

One study identified that professionals treated adolescents, daily or almost every day, however, as to the reason for seeking medical attention, it became clear that they sought it for the treatment of diseases, showing that the motive for seeking treatment was closely linked to clinical problems ${ }^{(1)}$.

Another study among adolescents showed that $16 \%$ of respondents interviewed referred to being treated for some illness, $82 \%$ evaluated their state of health as good or very good, and $48 \%$ affirmed they felt the need to seek a health service in the last three months ${ }^{(11)}$. They indicated the need to seek health services was also linked to preventive actions.

The level of normative participation + independence was identified when adolescents perceived health actions in a more broad sense, encompassing preventive and family care actions. At this level, the user did not attend the unit only for medication, but presented with a change of attitude toward prevention. Even still, the demand for health services was further characterized by the perceived need of users that there was a problem, the same as if it were a disease ${ }^{(6)}$.

The activities performed during home visits, in most cases, had an essentially curative and individual character(12), despite the proposal that the Family Health Strategy be extended to the family and home environment. It was also perceived during the observations that the approach taken to the adolescent, in this scenario, was always made to the individual complaining of illness, or requiring examinations or curative procedures, representing an obstacle to health promotion.

A relatively large percentage of professionals reported not engaging in any type of activity involving adolescent health education. A qualitative study, conducted with professionals of the FHS in Florianopolis, found that the training of health professionals was one of the central issues, in the context investigated, working in health education in the logic of health promotion required by $\mathrm{FHS}^{(13)}$.

The majority of the discourse was permeated by education focused on disease and in an attempt to change the behavior of individuals, with a vertical and impositive relationship. For this reason, the importance of ongoing education and restructuring of undergraduate courses is reiterated, in order to approximate the practice of education in health of the social reality ${ }^{(13)}$.

The critical conception of education, which aims to be an education for awareness and for change, solicits a close relationship between professionals and the population, in which the production of knowledge becomes a collective, creating a mutual modification, because both are carriers of distinct knowledge(14). 
At the level of emancipatory participation, the importance of the actions of health education in schools was recognized. In the process of searching for health promotion, the strategies of health education as a tool for transforming users into autonomous and participatory subjects in the process health were used(6).

Health education, as a pedagogical political process, requires the development of critical and reflexive thinking, allowing it to reveal reality and to propose transforming actions that lead the individual to autonomy and emancipation as a historical and social subject, able to propose and offer opinion on the decisions of health for self-care, for their family and the community ${ }^{(14)}$, enabling the rise of adolescents and the general community through the levels of the theoretical-methodological structure of an enabler to participation.

Almost all of the professionals reported they stimulated the participation of adolescents in the everyday life of the Family Health Strategy. The primary means by which professionals sought this occurred through the process of welcoming of this public into the health unit.

Welcoming, when done properly, allows the approximation of the professionals with the adolescents, which in turn, provides the development of a bond between them. The relevance of this lies in the fact of making adherence of the group to the proposals developed of care and educational activities by the professional staff easier, therefore, acting as an element of uptake of the adolescents into the health service.

In the implementation of the theoreticalmethodological structure of an enabler to participation, the level of transformative participation was identified when a small portion of users were involved with community problems and sought intersectoral coordination $^{(6)}$. In this study, we observed stimulation on the part of the professionals for adolescents to participate in acts of social control, therefore, the fourth level was not effectively identified.

The majority of the professionals affirmed that they conducted intersectoral activities, and they concentrated on activities performed in the schools, either by conducting educational actions or in the development of activities in the BHU. However, just over half of the professionals reported performing such activities, showing that the presence of the professionals in the school context still does not happen in an effective manner.

Few professionals mentioned not having the ability to work with the group of adolescents, characterizing a positive aspect, considering that this would be an obstacle to the care of this public.

Similar to what occurred in other cities, there were difficulties in everyday care related to the lack of structure and personnel, precariousness in the units, excessive prioritization of specific groups and predominance of curative-individual practices, as well as excess demand and professional work overload(15).

It is thought that there were several difficulties listed for adolescent participation in health services, some of which were more complex than others and required a reorientation of services, but principally, a reorganization of individual practices of each health professional involved in care of the health of the adolescent.

\section{Conclusion}

The study showed that adolescents still maintained their participation in primary health care, restricted to medical-care practices, with emphasis on disease and its treatment/control, emphasizing the detachment that the service and the professionals still impose on the adolescents and the urgent need for uptake of those adolescents.

It is important to consider that in this process of participation of the adolescents in the service, they are still encountered as passive subjects of care, difficult to conquer and conduct and, also, dependent on the reorganization of care practices. The adolescents, meanwhile, still did not see, in practice, the FHS as something that would contribute to the promotion of their health, which was reflected in their noneffective participation.

In this perspective, with the process of consolidation of the Family Health Strategy, an upward movement in the participation of adolescent users is expected, and consequently, a greater involvement of professionals in developing actions of capacitation of this clientele.

\section{References}

1. Ferrari RAP, Thomson Z, Melchio R. Adolescência: ações e percepção dos médicos e enfermeiros do Programa Saúde da Família. Interface - Comunic, Saúde, Educ. 2008;12(25):387-400.

2. Vieira RP, Machado MFAS, Bezerra IMPB, Machado CA. Assistência à saúde e demanda dos serviços na estratégia saúde da família: a visão dos adolescentes. Cogitare Enferm. 2011;6(4):714-20. 
3. Ferrari RAP, Thomson $Z$, Melchio R. Atenção à saúde dos adolescentes: percepção dos médicos e enfermeiros das equipes da saúde da família. Cad Saúde Pública. 2006;22(11):2491-5.

4. Ministério da Saúde (BR). Saúde integral de adolescentes e jovens: orientações para a organização de serviços de saúde. Brasília (DF): Ministério da Saúde; 2005.

5. Ministério da Saúde (BR). Promoção da saúde: Carta de Ottawa, Declaração de Adelaide, Declaração de Sundsvall, Declaração de Jacarta, Declaração de Bogotá. Brasília (DF): Ministério da Saúde; 2001.

6. Machado MFAS, Vieira NFC, Silva RM. Compreensão das mudanças comportamentais do usuário no Programa Saúde da Família por meio da participação habilitadora. Ciênc Saúde Coletiva. 2010;15(4):2133-43.

7. Ministério da Saúde (BR). Marco legal: saúde, um direito de adolescentes. Brasília (DF): Ministério da Saúde; 2005.

8. Machado MFAS, Vieira NFC. Estrutura teóricometodológica de participação habilitadora de usuários na Estratégia Saúde da Família. Enferm em Foco 2010;1(2):59-62.

9. Nogueira MJ, Modena CM, Schall VT. Políticas públicas voltadas para adolescentes nas unidades básicas de saúde no município de Belo Horizonte/MG: uma análise sob a perspectiva dos profissionais de saúde. Ver APS 2010;13(3):338-45.

10. Silva JM, Caldeira AP. Modelo assistencial e indicadores de qualidade da assistência: percepção dos profissionais da atenção primária à saúde Cad Saúde Pública. 2010;26(6):1187-93.

11. Claro LBL, March C, Mascarenhas MTM, Castro IAB, Rosa M LG. Adolescentes e suas relações com os serviços de saúde: estudo transversal em escolares de Niterói, Rio de Janeiro, Brasil. Cad Saúde Pública. 2006; 22(8): 1565-74.

12. Oliveira RG, Marcon SS. Trabalhar com famílias no Programa de Saúde da Família: a prática do enfermeiro em Maringá-Paraná. Rev Esc Enferm USP. 2007;41(1):65-72.

13. Besen CB, Netto MS, Da Ros MA, Silva FW, Silva CG, Pires MF. A estratégia saúde da família como objeto de educação em saúde. Saude Soc. 2007;16(1):57-68.

14. Machado MFAS, Monteiro EMLM, Queiroz DT, Vieira NFC, Barroso MGT. Integralidade, formação de saúde, educação em saúde e as propostas do SUS uma revisão conceitual. Ciênc Saúde Coletiva. 2007; 12(2):335-42.

15. Rocha PM, Uchoa AC, Rocha NSPD, Souza ECF, Rocha ML, Pinheiro TXA. Avaliação do Programa Saúde da Família em municípios do Nordeste brasileiro: velhos e novos desafios. Cad Saúde Pública. 2008; 24 Sup 1:S69-S78. 